\title{
Osteoid osteoma masquerading monoarthritis of the elbow
}

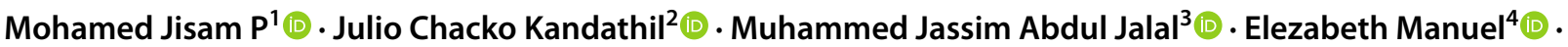 \\ Bipin Theruvil ${ }^{1}$
}

Received: 1 July 2021 / Revised: 30 July 2021 / Accepted: 5 August 2021 / Published online: 12 August 2021

(C) International League of Associations for Rheumatology (ILAR) 2021

\section{Presentation}

A 14-year-old boy was referred to a rheumatology clinic with left elbow pain, swelling, and stiffness for the past 6 months. His pain aggravated at night and was relieved with ibuprofen. He gave no history of polyarthralgia or morning stiffness. On examination, he had a diffuse swelling around the posterolateral aspect of the elbow. He had an effusion and a fixed flexion deformity of 40 degrees with further flexion to 120 degrees.

Radiographs of the distal humerus showed a well-defined radiolucent lesion with central calcification and adjacent diffuse sclerosis in the lateral aspect of the wall of the olecranon fossa (Fig. 1a). Multidetector computed tomography (MDCT) showed a cortical-based lesion with an intraarticular component and dense central mineralization (Fig. 1b). Post-contrast T1 fat-suppressed (FS) magnetic resonance images (MRI) demonstrated enhancement along the margins of the lesion, intense reactive synovitis, and joint effusion (Fig. 1c). The imaging findings were suggestive of an osteoid osteoma (OO). His hand radiographs did not show any evidence of periarticular osteopenia commonly seen in inflammatory arthritides. Radiographs of his lumbar spine did not show evidence of syndesmophyte/sacroiliitis.

Spontaneous onset symptoms with the absence of morning stiffness, normal blood counts, ESR, CRP, RA factor, ANA, ACCP, uric acid, and imaging ruled out inflammatory,

Mohamed Jisam P

drjisam@gmail.com

1 Department of Orthopaedics, VPS Lakeshore Hospital and Research Centre, Kochi 682040, India

2 Department of Radiodiagnosis, VPS Lakeshore Hospital and Research Centre, Kochi 682040, India

3 Department of Internal Medicine and Rheumatology, VPS Lakeshore Hospital and Research Centre, Kochi 682040, India

4 Department of Pathology, VPS Lakeshore Hospital and Research Centre, Kochi 682040, India infective, and traumatic causes of monoarthritis. The patient's characteristic history and the nidus on imaging were suggestive of an OO. We performed an image-guided excision biopsy with complete resolution of pain, stiffness, and synovitis. Microbiological examination of the bone, synovium, and fluid (normal bacteria and acid-fast bacilli) showed no growth. Histopathological examination (Fig. 1d) confirmed the diagnosis.

\section{Discussion}

$\mathrm{OO}$ is a self-limiting benign bone-forming tumor mostly seen in the second decade of life [1]. Prostaglandin synthesis has been shown to occur in the nidus and this is thought to be the reason for the relief of symptoms with non-steroidal anti-inflammatory drugs (NSAIDS) [2]. The intraarticular part of the $\mathrm{OO}$ is known to cause intense synovitis in the elbow and hip as most of the epiphysis even the metaphysis is localized within the synovial cavity [3]. This can mimic monoarthritis like in this case causing stiffness due to a mechanical block.

Although spontaneous regression over many years has been reported [4], most cases require surgery due to severe pain. The lesion could be ablated using a radiofrequency probe or excised using percutaneous or open methods [5].

If an adolescent presents with monoarthritis, inflammatory causes (rheumatoid arthritis, undifferentiated arthritis, and seronegative spondyloarthropathies), crystal deposition diseases (gout and pseudogout), infections (tuberculosis, Brodie's abscess, and septic arthritis), trauma, and neoplastic causes like OO should be considered. 
Fig. 1 a X-ray left elbow showing a radiolucent nidus with central calcification and adjacent sclerosis with reactive periosteal new bone formation laterally. b Coronal reformatted MDCT image shows a wellcircumscribed cortical-based lesion with lucent nidus, central mineralization, and eccentric intraarticular component projecting into the olecranon fossa. c MRI post-contrast sagittal T1 FS image showing enhancement of reactive synovitis, effusion, and adjacent diffuse marrow edema. d Microscopic $(4 \times$ Scanner and high power $40 \times$-inset) view shows a central nidus having anastomosing trabeculae of woven bone lined by osteoblast with periphery showing cortical bone.
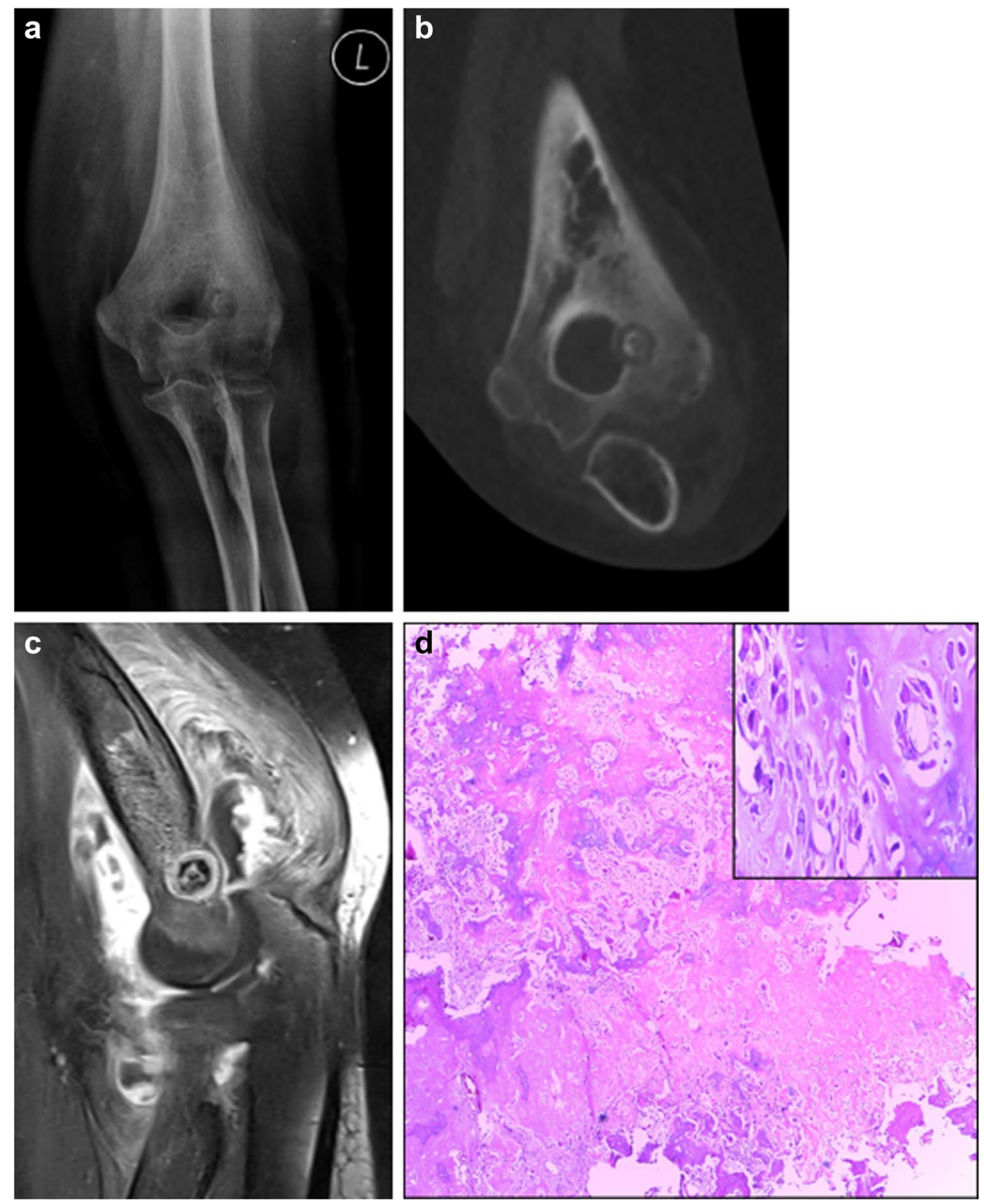

\section{Declarations}

Disclosures None.

Patient consent Obtained.

\section{References}

1. Lee EH, Shafi M, Hui JH (2006) Osteoid osteoma: a current review. Journal of Pediatric Orthopaedics 26(5):695-700. https:// doi.org/10.1097/01.bpo.0000233807.80046.7c

2. Ciftdemir M, Tuncel SA, Usta U (2015) Atypical osteoid osteomas. Eur J Orthop Surg Traumatol 25(1):17-27. https://doi.org/ 10.1007/s00590-013-1291-1
3. De Smet L (2000) Synovitis of the wrist joint caused by an intraarticular perforation of an osteoid osteoma of the radial styloid. Clin Rheumatol 19(3):229-230. https://doi.org/10.1007/s1006 70050163

4. Boscainos PJ, Cousins GR, Kulshreshtha R, Oliver TB, Papagelopoulos PJ (2013) Osteoid osteoma. Orthopedics 36(10):792-800. https://doi.org/10.3928/01477447-20130920-10

5. Roqueplan F, Porcher R, Hamzé B, Bousson V, Zouari L, Younan T, Laredo JD (2010) Long-term results of percutaneous resection and interstitial laser ablation of osteoid osteomas. Eur Radiol 20(1):209-217. https://doi.org/10.1007/s00590-013-1291-1

Publisher's note Springer Nature remains neutral with regard to jurisdictional claims in published maps and institutional affiliations. 